\title{
Estimating time to pregnancy in Chinese couples: a population-based study
}

\author{
Danni Zheng ${ }^{1}$, Zehong Zhou ${ }^{2}$, Rong $\mathrm{Li}^{3}$, Hongping $\mathrm{Wu}^{3}$, Suxin $\mathrm{Xu}^{3}$, Yuefan $\mathrm{Kang}^{3}$, Yunxia \\ $\mathrm{Cao}^{4}$, Xiujuan Chen ${ }^{3}$, Yimin $\mathrm{Zhu}^{3}$, Shuguang $\mathrm{Xu}^{3}$, Zi-Jiang Chen ${ }^{5}$, and Jie Qiao ${ }^{1}$ \\ ${ }^{1}$ Peking University Third Hospital \\ ${ }^{2}$ Guangzhou Women and Children's Medical Center \\ ${ }^{3}$ Affiliation not available \\ ${ }^{4}$ The First Affiliated Hospital of Anhui Medical University \\ ${ }^{5}$ Shandong Provincial Hospital Affiliated to Shandong University
}

June 22, 2020

\begin{abstract}
Objective: To explore the distribution of time to pregnancy in a Chinese population based on a cross-sectional design. Design: A cross-sectional population-based study. Setting: 8 provinces/municipalities in China between 2010 and 2011 . Population or Sample: 25,270 couples aged 20-49 years. Methods: Multistage stratified cluster sampling strategy was utilized to recruit participants from each stratum by district, province/municipality, town/township, and village/street order. Main Outcome Measures: Time to diagnose pregnancy from 17,275 couples "at risk for pregnancy". Results: In 7,889 couples eligible for analysis, the mean time to pregnancy was 17.2 months (standard deviation, 22.7) with a median of 9 months (25-75th percentile, 3-20 months). Women aged 20-24 years had the highest percentage of pregnancy at 3, 6, 12, and 24 months $(23.9 \%, 42.5 \%$, $58.5 \%$, and $80.4 \%$, respectively). Furthermore, $55.8 \%(3,413 / 6,116)$ and $79.9 \%(4,885 / 6,116)$ of women aged $<35$ years conceived within 1 year and 2 years, respectively, and the percentage increased by only $8.4 \%(5,399 / 6,116,88.8 \%)$ in the third year. Only $30.6 \%(186 / 607)$ and $50.6 \%$ (307/607) of women aged [?]35 years conceived within 1 year and 2 years, respectively. Risk factors associated with time to pregnancy were older age, lower educational attainment of couples, higher annual household income, toxic exposure in men, shorter duration of cohabitation, longer menstrual cycle interval, history of abnormal pregnancy, and nullipara. Conclusions: Our study provides a comprehensive estimation of the time to diagnose pregnancy among Chinese couples of reproductive age, providing important information for policy makers, fertility clinicians, and sexual health educators.
\end{abstract}

\section{Tweetable abstract}

This population-based study reports a comprehensive estimation of time to diagnose pregnancy among Chinese couples of reproductive ages, providing important information for policy makers, fertility clinicians, and sexual health educators.

\section{Introduction}

Most couples have life plans that include children, as parenthood is one of the most universally desired aims in adulthood. However, not all couples can achieve their desires, and a proportion of them will need medical help to solve reproductive issues. A remarkable demographic shift in recent years has affected female fecundity, including delayed childbearing age and changing lifestyles.(1) Estimating population-based fecundity is important for policy improvement in healthcare as these changes occur.

According to the International Committee for Monitoring Assisted Reproductive Technology and the World Health Organization, infertility is a disease of the reproductive system defined by the failure to achieve a 
clinical pregnancy after 12 months or more of regular unprotected sexual intercourse.(2) Previous studies have reported the prevalence of infertility among different populations in China (15.5\% in women attempting to conceive and $24.9 \%$ in women at risk for pregnancy) using the common definition of failure to conceive within the last 12 months.(3) Time to pregnancy (TTP), which is measured as the months or menstrual cycles from attempting to conceive until successful pregnancy, is gaining more attention as another measure of subfecundity or infertility.(4) In addition to estimating the cumulative probabilities of conception to prevent variation across different definitions and study designs,(5) this indicator can find suitable thresholds to determine the grades of subfertility and is more convenient to measure the distribution of epidemiology and the study mechanism of the biological process. $(6,7)$

Using TTP as a continuous indicator to estimate the likelihood of conception during a certain time, this study aimed to portray the fecundity of couples in a representative cross-sectional population of reproductive ages in China.

\section{Materials and Methods}

\section{Study design and population}

The current project is a large-scale population-based cross-sectional study conducted in northern and eastern China from 2010 to 2011. Details about sampling, eligibility, and investigation have been introduced elsewhere.(3) Briefly, our study utilized a multistage stratified cluster sampling strategy to recruit participants from each stratum by district, province/municipality, town/township, and village/street order (Figure S1). Couples were then approached by professional investigators with the assistance from local officials and communities. Ultimately, 25,270 couples were approached from 8 provinces/municipalities/cities (including Zhejiang, Anhui, Fujian, Shandong, Beijing, Hebei, Heilongjiang, and Nei Mongol) for their sexual and reproductive health information.Among these couples, 18,571 were interviewed, with a response rate of $74 \%$ $(18,571 / 25,270)$.

\section{Data collection}

Based on the results of a pilot study, a standardized and structured questionnaire was designed after discussion with gynecologists and epidemiologists. Face-to-face interviews were conducted by trained interviewers consisting of local community leaders and healthcare workers. In the investigation process, women were interviewed to recall information about their partners and themselves. Household interviews were carried out in private to assure the confidentiality of the information obtained.

Data on general demographic and socioeconomic status, physical measurements, lifestyle habits, and toxic exposure for both women and their partners were collected, including the region, age of couples (represented as the current age of the couple minus the number of years attempting to conceive and classified as 20-24, 2529, 30-34, 35-39, and [?] 40 years), ethnicity (Han ethnic group and minorities [including Mongol nationality, Hui nationality, and Zang nationality]), body mass index (BMI; in $\left.\mathrm{kg} / \mathrm{m}^{2}\right)$ of couples $(<18.50,18.50-23.99$, 24.00-27.99, and [?]28.00 kg/m²), educational level (primary school and below, middle school, high school, college and beyond), current occupation (employment [included clerk, professional worker, service worker, agricultural and related worker, factory worker], unemployment [referred to being a housewife, job loss, and retirement], and others or not stated), history of toxic exposure ("yes" [restricted to radioactive and toxic substances] or "no"), smoking ("yes" [defined as currently smoking at least once a week] or "no" (included those who never smoked and used to smoke]), drinking ("yes" [defined as currently drinking at least once a week] or "no" (included those who never drank and used to drink]), physical exercise (occasionally, 2-3 times a month, and at least once a week), and annual household income (low $[<10,000$ renminbi (RMB)], middle [10,000-19,999 RMB], or high [[?]20,000 RMB]). Additionally, reproductive health, marriage, and bearing status were asked, including the duration of cohabitation (represented as the original duration of cohabitation minus the number of years attempting to conceive), frequency of intercourse (1/day, $1 / 2-5$ days, $1 /$ week, 1/10-15 days and 1/month), menstrual cycle interval ([?]23, 24-35 and >35 days), history of abnormal pregnancy ("yes" [included a history of stillbirth, induced labor, spontaneous abortion, and ectopic pregnancy] or "no"), and parity (nullipara and multipara). 


\section{Eligibility and measurement of TTP}

Eligibility screening of the population, selection of the target analysis set, and extraction of data on TTP are presented in Figure 1. Among 18,571 participants who responded, women aged $<20$ or $>49$ years, extremes outside the $0.5-99.5^{\text {th }}$ percentile of continuous variables (BMI of women and men, age at menarche, duration of menstruation, pregnancy count, and number of uterine curettage), and couples who had separated for longer than 3 months in the past year were excluded from our study. Women who had not become pregnant within the last 12 months but had been attempting to conceive for $<12$ months were considered as logical error and excluded as well. Consequently, 17,275 participants who had not used contraception and had not separated from their spouse for longer than 3 months in the last year were defined as women "at risk for pregnancy" (Figure 1A). In this population, women were asked about their pregnancy status during the last year; those who had spontaneous pregnancy in the last year were subsequently asked, "How long have you been trying to conceive with this pregnancy?" Responses to these questions were used to determine their duration of current pregnancy attempt in a retrospective design among pregnant women (Group 1, fertile group). Women who did not conceive in the last year and had intercourse at $<1 /$ month were excluded. Subsequently, TTP was identified for the remaining participants via a series of questions: They were first asked about their willingness to become pregnant. For women who were attempting to conceive at the time of the investigation, the question "How long have you been trying to become pregnant?" was asked to obtain their TTP for estimation with the current-duration approach (Group 2, subfertile group). Women who did not want to become pregnant at the time of the investigation were excluded from our analysis for TTP (Figure 1B).

\section{Statistical analysis}

Statistical analyses were performed using SAS software package version 9.4. Standard descriptive statistics were used to describe the study population: continuous variables were described using mean and standard deviation (SD), whereas categorical variables were presented as percentages. Proportions of sociodemographic and reproductive health factors in Groups 1 and 2, as well as the variation between women who conceived and those who did not conceive within the last 12 months, were calculated using Pearson's chi-square test and Fisher's exact test, as appropriate.

In our study, TTP represented the elapsed time from attempting to conceive to confirmation of pregnancy among women who conceived within the last 12 months (retrospective design) or the time from attempting to conceive to the investigation time among women who had not still conceived (cross-sectional design). To estimate a TTP distribution, we used Kaplan-Meier curves for both populations, which could provide an estimation of TTP and allow censors for reason other than conception. To set up a better model, we censored observations longer than 120 months because of the small numbers as $95 \%$ extreme values. Cox regressions were subsequently applied to estimate the fecundability odds ratios (FORs) associated with sociodemographic and reproductive factors for TTP by both unadjusted and adjusted models. FORs estimate the odds of becoming pregnant in a woman's current cycle, conditional on not being pregnant in the previous cycle.(8) An FOR $<1$ indicates reduced fecundity or, equivalently, a longer TTP, whereas an FOR $>1$ represents a shorter TTP. We used the expected low-risk group in a regression model as the reference group according to previous literatures or clinical consensus, and results were presented with odds ratios and 95\% confidence intervals (CI) around the point estimate. Models were first run to estimate the crude FORs, and multivariable models were then fitted to adjust for potential risk factors for fecundability. Adjustments included age, ethnicity, educational level, employment status, history of toxic exposure, smoking and drinking status of couples, frequency of physical exercise in women, annual household income of the family, duration of cohabitation (years), menstrual cycle interval, history of abnormal pregnancy, and parity. Likelihood ratio tests were used to compare the fit of models containing different variables to test for departures from a linear trend in ordered categorical variables. Differences with a $P$ value of $<.05$ were considered statistically significant.

\section{Ethical approval}

Informed consent forms were signed by all participants before our investigation. This survey was reviewed 
and approved by the Ethics Committee of Peking University Third Hospital (No. 2006FC001) and adheres to the ethical standards for human experimentation established in the Declaration of Helsinki and its later amendments.

\section{Results}

\section{Sample characteristics}

Among 17,275 women deemed at risk for pregnancy, 6,981 (40.4\%) had spontaneous pregnancy in the last year, which composed Group 1 at the time of the investigation $(5,422 / 6,981,77.7 \%)$ after excluding missing values for TTP $(1,543 / 6,981,22.1 \%)$ and couples with TTP $>120$ months $(16 / 6,981,0.2 \%)$ (fertile group ). Except for 234 missing values $(234 / 17,275,1.4 \%), 10,060(58.2 \%)$ out of 17,275 women did not conceive in the last year. When asked if they were willing to become pregnant, 3,328 couples answered "yes"; of these 3,328 couples, 2,467 (74.1\%) were subsequently selected as Group 2 after excluding missing values $(497 / 3,328,14.9 \%)$ and couples with TTP $>120$ months $(364 / 3,328,10.9 \%)$, which could be regarded as the population with a subfertile status at the time of the investigation (subfertile group ). After excluding 6,040 $(35.0 \%)$ out of 17,275 women who were not willing to become pregnant, a total of $7,889(45.7 \%)$ women conceived or had been attempting to become pregnant in the last year (Figure 1B).

As presented in Table 1, couples in Group 2 were older than those in Group 1 (women: $26.4 \pm 4.9$ [mean $\pm \mathrm{SD}$ ] years in Group 2 vs. $25.6 \pm 4.3$ years in Group 1; men: $28.5 \pm 5.2$ years in Group 2 vs. $27.6 \pm$ 4.8 years in Group 1). Group 2 had a higher proportion of currently overweight men $\left(23.0 \pm 2.2 \mathrm{~kg} / \mathrm{m}^{2}\right.$ in Group 2 vs. $22.7 \pm 2.2 \mathrm{~kg} / \mathrm{m}^{2}$ in Group 1). Couples in Group 1 were more educated than those in Group 2, and couples in Group 2 had higher annual income. More subfertile couples were exposed to toxic substances (women: $3.8 \%$ in Group 2 vs. 1.4\% in Group 1; men: 5.7\% in Group 2 vs. $3.3 \%$ in Group 1). Furthermore, male spouses were more likely to smoke ( $45.7 \%$ in Group 2 vs. $42.7 \%$ in Group 1) in the subfertile group. Subfertile women tended to have longer duration of cohabitation (6.1 \pm 4.8 years in Group 2 vs. $3.7 \pm 3.7$ years in Group 1), and $8.9 \%$ of women in the subfertile group had a menstrual cycle interval longer than 35 days (vs. $2.9 \%$ of women in the fertile group). The proportion of multiparous women and women with a positive history of abnormal pregnancies was higher in the fertile group (33.1\% in Group 1 vs. $29.0 \%$ in Group 2 and $89.5 \%$ in Group 1 vs. $85.9 \%$ in Group 2, respectively).

\section{Estimation of TTP}

Figure 2A shows the estimated survival function of TTP up to 120 months, which corresponded to the elapsed time from stopping contraception to confirmation of pregnancy or until the time of the investigation in both populations of Groups 1 and 2. The mean \pm SD for TTP in our study was $17.2 \pm 22.7$, with a median duration of 9 months and $25-75^{\text {th }}$ percentiles of 3-20 months. The estimated proportion of couples who had conceived was $18.3 \%(\mathrm{n}=1,447)$ at 3 months, $37.0 \%(\mathrm{n}=2,919)$ at 6 months, $53.4 \%(\mathrm{n}=4,216)$ at 12 months, $76.7 \%(\mathrm{n}=6,047)$ at 24 months, and $85.6 \%(\mathrm{n}=6,753)$ at 36 months (Table 2$)$. Additionally, we represented different age patterns in women with the same method (Figure 2B). A similar scenario was also presented for the population in Group 1 (Figure 2C and Figure 2D). As can be drawn from the diagram, related curves dropped more slowly, with visible [?]30-year differences in age among subgroups.

Furthermore, we estimated the proportions of TTP at 3, 6, 12, 24, and 36 months among different age populations (Table 2). Women aged 20-24 years had the highest percentage of pregnancy at 3,6,12, and 24 months $(23.9 \%, 42.5 \%, 58.5 \%$, and $80.4 \%$, respectively). Additionally, $55.8 \%(3,413 / 6,116)$ and $79.9 \%$ $(4,885 / 6,116)$ of women aged $<35$ years conceived within 1 year and 2 years, respectively, and the percentage increased by only $8.4 \%(5,399 / 6116,88.3 \%)$ in the third year. However, only $30.6 \%(186 / 607)$ and $50.6 \%$ (307/607) of women aged [?]35 years conceived at 1 year and 2 years, respectively.

\section{Associated factors for TTP}

Cox regression calculations revealed factors that considerably impaired the probability of pregnancy (Table 3 ). In an adjusted model, older groups had significantly longer estimated TTP than the group aged 20-24 
years. Women with lower educational attainment tended to have longer TTPs than those with higher educational attainment (adjusted FOR $=1.31$, 95\% CI: 1.04-1.64 for women with college and higher educational level). Women without full-time work were more likely to become pregnant than employed women (adjusted $\mathrm{FOR}=1.60,95 \% \mathrm{CI}:$ 1.48-1.73 for unemployed women). As shown in Table 1, couples with a higher annual household income had impaired probability of conception than couples with a lower income (adjusted $\mathrm{FOR}=0.75,95 \% \mathrm{CI}: 0.67-0.84$ for households with an income of more than 20,000 RMB). With respect to reproductive characteristics, couples who had a longer duration of cohabitation (FOR=1.06, 95\% CI: $1.05-$ $1.07)$ or were multiparous $(\mathrm{FOR}=1.13,95 \% \mathrm{CI}: 1.02-1.25)$ had shorter TTP than those who had a shorter duration of cohabitation or were uniparous. Other factors that could potentially reduce the probability of pregnancy included toxic exposure in men, longer menstrual cycle interval, and history of abnormal pregnancy. All other factors evaluated in our study did not have a statistically significant influence on pregnancy rates.

\section{Discussion}

\section{Main Findings}

In this cross-sectional study of sampled couples aged 20-49 years, we described the TTP distribution via survival analysis. The mean +- SD for TTP in our study was $17.2+-22.7$ months. Women aged 20-24 years had the highest percentage of pregnancy at 3, 6, 12, and 24 months. Approximately $56 \%$ and $80 \%$ of women aged $<35$ years conceived within 1 year and 2 years, respectively. Only about $30 \%$ and $50 \%$ of women older than 35 years conceived at 1 year and 2 years, respectively. In addition to the consecutive distribution of fecundity, we found several associated risk factors for TTP, including older age of couples, lower current BMI of women, lower educational attainment of women, higher annual household income, toxic exposure in men, shorter duration of cohabitation, longer menstrual cycle interval, history of abnormal pregnancy, and nullipara. To the best of our knowledge, our study is one of the first to indicate the TTP distribution in a representative Chinese population combined with cross-sectional and retrospective study designs.

\section{Strengths and limitations}

This study has several limitations that need to be noted. First, given the characteristics and temporal nature of our cross-sectional design, it was impossible to make a causal inference between potential associated factors and subfertility or infertility (presented as longer TTP in our study). Second, information on TTP and other measures was self-reported, which might introduce recall bias. To resolve this problem, we designed a set of questions to collect accurate data on duration among different populations, and logical errors were further excluded from the final analysis. Third, we only enrolled couples who conceived or were attempting to conceive at the time of the investigation instead of couples without intent to become pregnant, which might not be representative of women at risk for pregnancy. However, not all couples who engaged in unprotected sex without intention to conveive were whom truly desired to become pregnant, and the quality of information on TTP in this population is probably poorer. Finally, our data were collected from 2010 to 2011 , when only couples who were both "only children" were encouraged to have their second child in China. Interpretation of the results for such group under complicated political restrictions is challenging.

Nevertheless, our study has obvious strengths. First, the integration of both retrospective and cross-sectional designs was applied. Thus, we not only analyzed TTP in pregnant women but also utilized current approaches to examine TTP in women attempting to conceive. Second, the couples in our study were sampled from the general population with adequate representation, making it possible to inquire the TTP in cases of unsuccessful attempts and infertility. Third, dissimilar to other several population-based studies that used traditional binary classification to estimate infertility with "yes" or "no," our study acquired the total TTP distribution in couples at risk for pregnancy, which provided a more sensitive indicator of fecundity and its associated risk factors. Finally, this approach could facilitate comparisons across different types of population-based and clinical studies, which might help improve the public health guidelines and clinical recommendations.

\section{Interpretation}




\section{Results in context}

Researchers have previously provided different estimations of TTP from various kinds of studies with retrospective, prospective, or cross-sectional designs. (5, 9-13) Several results for both pregnant and nonpregnant women were obtained from these studies, which are comparable to the findings of our study. A populationbased survey across Denmark, Germany, Poland, Italy, and Spain investigated 6,630 women aged 25-44 years and collected data on their time of unprotected intercourse either leading or not leading to pregnancy.(14) Among these women, 23.4\% did not conceive within 12 months, and the highest proportion occurred in Poland (33.3\%). Another cross-sectional study from South Africa collected data on TTP from the most recent pregnancy of 1,121 women aged 18-49 years, including women who conceived and women still attempting to conceive.(11) The percentage of women who were not pregnant after 3, 6, 12, and 24 months was $67 \%, 50 \%, 32 \%$, and $17 \%$, respectively. The TTP observed in our study was comparable to that previously described by prior studies - that is, $81.7 \%, 63.0 \%, 46.6 \%, 23.3 \%$, and $14.4 \%$ of couples still would not have conceived at $3,6,12,24$, and 36 months, respectively.

Notably, $56 \%$ of women aged $<35$ years conceived within 1 year, and the percentage reached $80 \%$ within 2 years of initiating attempt. However, for women older than 35 years, the probability of natural conception was as low as $30 \%$ and $50 \%$ at 1 year and 2 years, respectively. Infertility has been demonstrated to be related to individual psychological burden, intimate partner violence, unsafe sexual behavior, social stigma and isolation, mental or other health implications, and even financial difficulty. $(15,16)$ Couples are suggested to seek medical help if they fail to conceive after 1 year of attempt. For women aged 35 years or older, the suggested attempt duration is 6 months before they are encouraged to receive evaluation or treatment.(17) From a public health perspective, it might be beneficial if they resort to intervention early. With the global development of assisted reproductive technology (ART), it is easier to receive treatment nowadays, and some institutes even routinely perform intra-cytoplasmic sperm injection for infertile couples.(18) As revealed in our results, women aged $<35$ years still have a high probability of achieving natural pregnancy within 2 years.

Under the circumstances of rapid societal development, pressures that couples commonly confront are unprecedented and could also affect their fecundity.(19) Additionally, the diagnosis of infertility imposes considerable spiritual burden. However, stress and anxiety concerning infertility are often overlooked and little time is left for couples to adjust.(20) Although ART has been hugely beneficial in treating infertility, ART might not be the only solution for young couples who cannot conceive within 1 year. Perhaps more attention and patience should be paid to couples' mental health, and more of an effort could be made to help couples achieve natural pregnancy through addressing mental health issues first.

Compared with the analysis of risk factors associated with constructed measures of infertility, the analysis of TTP could explore related factors with better time sequences. Therefore, we also found related risk factors for impaired fecundity by using a Cox regression model. Consistent with the results of previous studies in the literature, age had a significant effect on couples' TTP in our study. Furthermore, in our study, socioeconomic status such as educational level and household income was related to TTP: TTP was shorter in couples with higher educational attainment, which was mainly attributable to their healthier lifestyle(21) and successful use of preventive and curative care.(22) Results in our population revealed that high-income couples had longer TTPs compared with the low-income group. It was well established that high fertility was associated with poverty $(23)$ and could be explained by the fact that high-income couples in China tend to postpone the timing of pregnancy and can experience induced abortion, which might increase their possibilities of suffering from infertility.(3) In our study, exposure to radioactive and toxic substances increased related TTP in men, which has been confirmed in lots of related literature of both human and animal species.(24, 25) Therefore, a safe work environment was said to be a key factor for normal male fertility.(26)

\section{Clinical and research implications}

Human reproduction is a complex sequence of physiological procedures starting with gamete development, fertilization, implantation, and embryonic development until birth.(12) Currently, with the relaxation of 
population policies as well as changes in parenting attitudes and lifestyles among young couples, the trend toward "backward" childbearing age is gaining attention. In addition, increased changes in environmental exposures, chromosome abnormalities, lifestyles, and unexplained factors have exacerbated infertility.(2729) Prevalence of infertility using constructed methods have been extensively studied.(30, 31) Within the same study design and database, we previously utilized a dichotomized method to estimate prevalence of infertility in different populations: the rate was $15.5 \%$ in women at risk for pregnancy while $25 \%$ in women actively attempting to conceive.(3) Rather than constructed measures of infertility as a parametric indicator, TTP can present the cumulative probability of pregnancy during a certain time period. These cumulative pregnancy prospects will help researchers grasp the comprehensive distribution of human fecundity and decide the appropriate timing for fertility treatment.

TTP can be obtained from various epidemiological designs. The most common method is to ask pregnant women to retrospectively recall their time to conception, which is easy to access with lower costs and has been described well. $(9,13,32,33)$ However, this design may introduce recall bias and neglect infertile couples who did not become pregnant.(34) In contrast, a prospective design has been recognized as the "gold standard" to estimate TTP, as it can recruit eligible couples before their attempts and follow up their exact duration with regular laboratory tests. $(5,10,12,35)$ However, this may be less cost-effective for a national population level and less representative when only focusing on pregnancy planners.(36) The current-duration approach has become popular in recent years as it can obtain TTP from couples who are actively attempting to conceive via a cross-sectional study with less recall bias and better representation from the general population.(1, 13, 32) This study design also has its weakness: 1 . This method excludes couples with successful pregnancy within the investigated time, causing low fecundity in the certain sampled population. 2. The TTP in these studies only include couples with the current intention to conceive, who may differ in their pregnancy intention and recognition of fertility status compared with all couples at risk for pregnancy.(11) For our investigation process, we asked women whether they were pregnant within the last 12 months and recorded their TTP for the positive answer. For women who did not conceive within the last 12 months, a simple question was asked to determine whether they were currently attempting to conceive and, if so, for how long they had attempted. Based on this cross-sectional design, our study investigated both women who conceived within the past 12 months and women who did not but had been actively attempting to conceive at the time of the interview. Consequently, we collected data on their time until diagnosis of pregnancy with either a retrospective design (among pregnant women) or the current-duration approach (among women who did not become pregnant but were attempting to conceive). This method could, to some extent, overcome the limitations of previous retrospective designs and simple current-duration approaches with minimal selection bias and enlargement of the represented population.

\section{Conclusion}

Our study provides a comprehensive estimation of the TTP among Chinese couples of reproductive age. Over half of women aged $<35$ years would conceive within 1 year, the proportion of which increased to $80 \%$ at 2 years. Conversely, the probability of natural conception among women older than 35 years was only half that within 2 years. Along with the TTP distribution in Chinese couples, this study also detected related risk factors for fecundity such as age, toxic exposure, and socioeconomic status. Although the diagnosis and treatment of subfertility or infertility are becoming more accurate and less invasive, there remains a need to explore the overall fecundity of couples in order to guide clinicians toward the appropriate timing of treatment. Hence, the results of our study provide important information for policy makers to improve sexual health education for couples of reproductive age.

\section{Acknowledgements}

We thank thousands of healthcare workers who have contributed to data collection at the provincial, city, township, and village levels. We appreciate Professor He-Feng Huang (Chairman of the Department of Reproductive Endocrinology, Women's Hospital, School of Medicine, Zhejiang University at the time of the survey) for her coordination of the investigation in Zhejiang Province. We also thank Professor Canquan 
Zhou (Chairman of Chinese Society of Reproductive Medicine at the time of the survey) for his coordination and organization throughout the implementation of the project. Furthermore, we appreciate the efforts of Doctor Geng Yu during the preparation and execution phases of this study and express our gratitude to Doctor Elyssa Metas (Creighton University School of Medicine/Valleywise Health Medical Center, Phoenix, AZ, USA) for her help with editing this article for language. All individuals named in our acknowledgements provided consent and reported no conflict of interest.

\section{Disclosure of Interests}

The authors report no conflict of interest.

\section{Contribution to Authorship}

D.Z. conducted data analysis and drafting the article. Z.Z. have drafted and revised the article. H.W. conducted the organization and implementation of project as secretary and participated in the investigation of Beijing. R.L. contributed to the acquisition of Beijing's data, and revising the article for important intellectual content. S.X., Y.K., Y.C., X.C., Y.Z., S.X. and Z.C. did the specific data interpretation of Hebei, Fujian, Anhui, Nei Mongol, Zhejiang, Heilongjiang and Shandong provinces, respectively. J.Q. contributed to conception and design, final approval of the version to be published as corresponding author.

\section{Ethical approval}

Informed consent forms were signed by all participants before our investigation. This survey was reviewed and approved by the Ethics Committee of Peking University Third Hospital (No. 2006FC001) and adheres to the ethical standards for human experimentation established in the Declaration of Helsinki and its later amendments.

\section{Funding}

This study was supported by the National Key Research and Development Program (No. 2018YFC1002102), the Assisted Reproductive Technology Development Cooperation Projects from the Center for International Exchanges and Cooperation in the National Health and Family Planning Commission of the People's Republic of China (No. (2010)237), the National Key Research and Development Program of China (No. 2016YFC1000201), and the Capital Health Research and Development of Special (No. 2018-1-4091). The study funders had no role in the study design, implementation, analysis, manuscript preparation, or decision to submit this article for publication.

\section{References}

1. Thoma ME, McLain AC, Louis JF, King RB, Trumble AC, Sundaram R, et al. Prevalence of infertility in the United States as estimated by the current duration approach and a traditional constructed approach. FERTIL STERIL. 2013;99(5):1324-31.

2. Zegers-Hochschild F, Adamson GD, de Mouzon J, Ishihara O, Mansour R, Nygren K, et al. International Committee for Monitoring Assisted Reproductive Technology (ICMART) and the World Health Organization (WHO) revised glossary of ART terminology, 2009. FERTIL STERIL. [Dictionary]. 2009 2009-11-01;92(5):1520-4.

3. Zhou Z, Zheng D, Wu H, Li R, Xu S, Kang Y, et al. Epidemiology of infertility in China: a populationbased study. BJOG. [Journal Article]. 2018 2018-03-01;125(4):432-41.

4. Weinberg CR, Baird DD, Rowland AS. Pitfalls inherent in retrospective time-to-event studies: the example of time to pregnancy. STAT MED. [Journal Article]. 1993 1993-05-15;12(9):867-79.

5. Gnoth C, Godehardt D, Godehardt E, Frank-Herrmann P, Freundl G. Time to pregnancy: results of the German prospective study and impact on the management of infertility. HUM REPROD. [Journal Article]. 2003 2003-09-01;18(9):1959-66. 
6. Olsen J, Kuppers-Chinnow M, Spinelli A. Seeking medical help for subfecundity: a study based upon surveys in five European countries. FERTIL STERIL. [Journal Article; Multicenter Study; Research Support, Non-U.S. Gov’t]. 1996 1996-07-01;66(1):95-100.

7. Joffe M, Key J, Best N, Keiding N, Scheike T, Jensen TK. Studying time to pregnancy by use of a retrospective design. AM J EPIDEMIOL. [Journal Article; Research Support, Non-U.S. Gov't; Review]. 2005 2005-07-15;162(2):115-24.

8. Velez MP, Arbuckle TE, Fraser WD. Maternal exposure to perfluorinated chemicals and reduced fecundity: the MIREC study. HUM REPROD. [Journal Article; Research Support, Non-U.S. Gov't]. 2015 2015-0301;30(3):701-9.

9. Louis JF, Thoma ME, Sorensen DN, McLain AC, King RB, Sundaram R, et al. The prevalence of couple infertility in the United States from a male perspective: evidence from a nationally representative sample. ANDROLOGY-US. [Journal Article; Research Support, N.I.H., Extramural; Research Support, N.I.H., Intramural; Research Support, U.S. Gov't, Non-P.H.S.; Research Support, U.S. Gov't, P.H.S.]. 2013 2013-09-01;1(5):741-8.

10. Issa Y, Sallmen M, Nijem K, Bjertness E, Kristensen P. Fecundability among newly married couples in agricultural villages in Palestine: a prospective study. HUM REPROD. [Journal Article; Research Support, Non-U.S. Gov't]. 2010 2010-08-01;25(8):2132-8.

11. Bello B, Kielkowski D, Heederik D, Wilson K. Time-to-pregnancy and pregnancy outcomes in a South African population. BMC PUBLIC HEALTH. [Journal Article; Research Support, Non-U.S. Gov't; Validation Studies]. 2010 2010-09-21;10:565.

12. Ziller V, Heilmaier C, Kostev K. Time to pregnancy in subfertile women in German gynecological practices: analysis of a representative cohort of more than 60,000 patients. ARCH GYNECOL OBSTET. [Journal Article]. 2015 2015-03-01;291(3):657-62.

13. Slama R, Hansen OKH, Ducot B, Bohet A, Sorensen D, Giorgis Allemand L, et al. Estimation of the frequency of involuntary infertility on a nation-wide basis. HUM REPROD. 2012 2012-05-01;27(5):1489-98.

14. Karmaus W. Infertility and subfecundity in population-based samples from Denmark, Germany, Italy, Poland and Spain. The European Journal of Public Health. 1999 1999-01-01;9(3

):229-35.

15. Stellar C, Garcia-Moreno C, Temmerman M, van der Poel S. A systematic review and narrative report of the relationship between infertility, subfertility, and intimate partner violence. Int J Gynaecol Obstet. [Journal Article; Review; Systematic Review]. 2016 2016-04-01;133(1):3-8.

16. Rouchou B. Consequences of infertility in developing countries. Perspect Public Health. [Journal Article; Review]. 2013 2013-05-01;133(3):174-9.

17. Evers JL. Female subfertility. LANCET. [Journal Article; Review]. 2002 2002-07-13;360(9327):151-9.

18. Boulet SL, Mehta A, Kissin DM, Warner L, Kawwass JF, Jamieson DJ. Trends in use of and reproductive outcomes associated with intracytoplasmic sperm injection. JAMA. [Comparative Study; Journal Article; Research Support, N.I.H., Extramural]. 2015 2015-01-20;313(3):255-63.

19. Schmidt L, Sobotka T, Bentzen JG, Nyboe AA. Demographic and medical consequences of the postponement of parenthood. HUM REPROD UPDATE. [Journal Article; Review]. 2012 2012-01-01;18(1):29-43.

20. Asemota OA, Klatsky P. Access to infertility care in the developing world: the family promotion gap. SEMIN REPROD MED. [Journal Article; Review]. 2015 2015-01-01;33(1):17-22.

21. Mackenbach JP. The persistence of health inequalities in modern welfare states: the explanation of a paradox. SOC SCI MED. [Journal Article]. 2012 2012-08-01;75(4):761-9. 
22. Partridge S, Balayla J, Holcroft CA, Abenhaim HA. Inadequate prenatal care utilization and risks of infant mortality and poor birth outcome: a retrospective analysis of 28,729,765 U.S. deliveries over 8 years. Am J Perinatol. [Journal Article]. 2012 2012-11-01;29(10):787-93.

23. Hammarberg K, Kirkman M. Infertility in resource-constrained settings: moving towards amelioration. REPROD BIOMED ONLINE. [Journal Article]. 2013 2013-02-01;26(2):189-95.

24. Petraglia F, Serour GI, Chapron C. The changing prevalence of infertility. Int J Gynaecol Obstet. [Journal Article]. 2013 2013-12-01;123 Suppl 2:S4-8.

25. Homan GF, Davies M, Norman R. The impact of lifestyle factors on reproductive performance in the general population and those undergoing infertility treatment: a review. HUM REPROD UPDATE. [Journal Article; Review]. 2007 2007-05-01;13(3):209-23.

26. Czene K, Lichtenstein P, Hemminki K. Environmental and heritable causes of cancer among 9.6 million individuals in the Swedish Family-Cancer Database. INT J CANCER. [Journal Article]. 2002 2002-0510;99(2):260-6.

27. Gelbaya TA, Potdar N, Jeve YB, Nardo LG. Definition and epidemiology of unexplained infertility. OBSTET GYNECOL SURV. [Journal Article]. 2014 2014-02-01;69(2):109-15.

28. Vander BM, Wyns C. Fertility and infertility: Definition and epidemiology. CLIN BIOCHEM. [Journal Article; Review]. 2018 2018-12-01;62:2-10.

29. De Jonge C, Barratt C. The present crisis in male reproductive health: an urgent need for a political, social, and research roadmap. ANDROLOGY-US. [Journal Article]. 2019 2019-11-01;7(6):762-8.

30. Boivin J, Bunting L, Collins JA, Nygren KG. International estimates of infertility prevalence and treatment-seeking: potential need and demand for infertility medical care. HUM REPROD. [Journal Article; Research Support, Non-U.S. Gov't]. 2007 2007-06-01;22(6):1506-12.

31. Gurunath S, Pandian Z, Anderson RA, Bhattacharya S. Defining infertility-a systematic review of prevalence studies. HUM REPROD UPDATE. [Journal Article; Review]. 2011 2011-09-01;17(5):575-88.

32. Polis CB, Cox CM, Tuncalp O, McLain AC, Thoma ME. Estimating infertility prevalence in low-tomiddle-income countries: an application of a current duration approach to Demographic and Health Survey data. HUM REPROD. 2017 2017-05-01;32(5):1064-74.

33. Muller A, Slama R, Labbe-Decleves C, Jouannet P, Bujan L, Mieusset R, et al. Geographic variations in probability of pregnancy in four cities of France. Rev Epidemiol Sante Publique. [Journal Article; Multicenter Study; Research Support, Non-U.S. Gov't]. 2006 2006-02-01;54(1):55-60.

34. Gnoth C, Godehardt E, Frank-Herrmann P, Friol K, Tigges J, Freundl G. Definition and prevalence of subfertility and infertility. HUM REPROD. [Journal Article; Review]. 2005 2005-05-01;20(5):1144-7.

35. Bonde JP, Ernst E, Jensen TK, Hjollund NH, Kolstad H, Henriksen TB, et al. Relation between semen quality and fertility: a population-based study of 430 first-pregnancy planners. LANCET. [Journal Article; Research Support, Non-U.S. Gov't]. 1998 1998-10-10;352(9135):1172-7.

36. Olsen J. Design options and sources of bias in time-to-pregnancy studies. Scand J Work Environ Health. [Journal Article; Research Support, Non-U.S. Gov’t]. 1999 1999-01-19;25 Suppl 1:5-7, 76-8.

Tables

Table 1 Demographic, socioeconomic, and reproductive characteristics of the study participants according to different groups

\begin{tabular}{lll}
\hline Characteristics & Women & Women \\
\hline & Group 1 $(\%)^{\mathrm{a}}$ & Group 2 $(\%)^{\mathrm{b}}$
\end{tabular}




\begin{tabular}{|c|c|c|}
\hline Characteristics & Women & Women \\
\hline \multicolumn{2}{|l|}{ Region } & $2,467(100.0)$ \\
\hline Anhui & $1,317(24.3)$ & $450(18.2)$ \\
\hline Beijing & $261(4.8)$ & $170(6.9)$ \\
\hline Fujian & $853(15.7)$ & $130(5.3)$ \\
\hline Hebei & $1,638(30.2)$ & $897(36.4)$ \\
\hline Heilongjiang & $405(7.5)$ & $137(5.6)$ \\
\hline Nei Mongo & $397(7.3)$ & $168(6.8)$ \\
\hline Zhejiang & $551(10.2)$ & $515(20.9)$ \\
\hline$P$ value & $<.01$ & $<.01$ \\
\hline \multicolumn{3}{|l|}{ Age $^{c}$, years } \\
\hline $20-24$ & $2,297(49.5)$ & $856(41.2)$ \\
\hline $25-29$ & $1,617(34.8)$ & $704(33.9)$ \\
\hline $30-34$ & $463(10.0)$ & $179(8.6)$ \\
\hline $35-39$ & $234(5.0)$ & $315(15.2)$ \\
\hline 40 & $33(0.7)$ & $24(1.2)$ \\
\hline Mean (SD) & $25.6(4.3)$ & $26.4(4.9)$ \\
\hline$P$ value & $<.01$ & $<.01$ \\
\hline \multicolumn{3}{|l|}{ Ethnicity } \\
\hline Han ethnic group & $5,259(97.4)$ & $2,379(97.3)$ \\
\hline Minorities $^{\mathrm{d}}$ & $139(2.6)$ & $65(2.7)$ \\
\hline$P$ value & $\mathrm{NS}$ & NS \\
\hline \multicolumn{3}{|l|}{ Current BMI, kg/m $\mathbf{m}^{2}$} \\
\hline$<18.50$ & $271(5.0)$ & $166(6.8)$ \\
\hline $18.50-23.99$ & $3,781(70.3)$ & $1,738(71.0)$ \\
\hline $24.00-27.99$ & $1,187(22.1)$ & $481(19.7)$ \\
\hline 28.00 & $136(2.5)$ & $63(2.6)$ \\
\hline Mean (SD) & $22.4(2.5)$ & $22.1(2.6)$ \\
\hline$P$ value & $<.01$ & $<.01$ \\
\hline \multicolumn{3}{|l|}{ Education } \\
\hline Primary school and below & $312(5.8)$ & $188(7.6)$ \\
\hline Middle school & $3,307(61.1)$ & $1,527(62.0)$ \\
\hline High school & $947(17.5)$ & $396(16.1)$ \\
\hline College and beyond & $844(15.6)$ & $352(14.3)$ \\
\hline$P$ value & $<.01$ & $<.01$ \\
\hline \multicolumn{3}{|l|}{ Occupation } \\
\hline Clerk & $346(6.4)$ & $157(6.4)$ \\
\hline Professional worker & $258(4.8)$ & $198(8.1)$ \\
\hline Service worker & $553(10.2)$ & $438(17.8)$ \\
\hline Agricultural and related worker & $1,491(27.6)$ & $688(28.0)$ \\
\hline Factory worker & $111(2.1)$ & $92(3.7)$ \\
\hline Unemployed & $2,408(44.5)$ & $599(24.4)$ \\
\hline Others or not stated & $243(4.5)$ & $285(11.6)$ \\
\hline$P$ value & $<.01$ & $<.01$ \\
\hline \multicolumn{3}{|c|}{ Annual household income, yuan } \\
\hline$<10,000$ & $3,214(60.0)$ & $1,298(53.2)$ \\
\hline $10,000-19,999$ & $1,288(24.1)$ & $602(24.7)$ \\
\hline$>20,000$ & $853(15.9)$ & $538(22.1)$ \\
\hline$P$ value & $<.01$ & $<.01$ \\
\hline
\end{tabular}




\begin{tabular}{|c|c|c|}
\hline Characteristics & Women & Women \\
\hline Yes & $73(1.4)$ & $90(3.8)$ \\
\hline No & $5,176(98.61)$ & $2,291(96.2)$ \\
\hline$P$ value & $<.01$ & $<.01$ \\
\hline \multicolumn{3}{|l|}{ Smoking } \\
\hline Yes & $18(0.3)$ & $13(0.5)$ \\
\hline $\mathrm{No}^{\mathrm{f}}$ & $5,399(99.7)$ & $2,449(99.5)$ \\
\hline$P$ value & NS & NS \\
\hline \multicolumn{3}{|l|}{ Drinking } \\
\hline Yes & $88(1.6)$ & $40(1.6)$ \\
\hline $\mathrm{No}^{\mathrm{g}}$ & $5,324(98.4)$ & $2,417(98.4)$ \\
\hline$P$ value & NS & NS \\
\hline \multicolumn{3}{|l|}{ Physical exercise } \\
\hline Occasionally & $4,551(84.7)$ & $1,992(82.0)$ \\
\hline $2-3$ times a month & $632(11.8)$ & $344(14.2)$ \\
\hline At least once a week & $193(3.6)$ & $94(3.9)$ \\
\hline$P$ value & $<.01$ & $<.01$ \\
\hline Duration of cohabitation, years ${ }^{h}$ & Duration of cohabitation, years ${ }^{h}$ & Duration of cohabitation, years ${ }^{h}$ \\
\hline Mean (SD) & $3.7(3.7)$ & $6.1(4.8)$ \\
\hline Menstrual cycle interval (day) ${ }^{i}$ & Menstrual cycle interval (day) ${ }^{i}$ & Menstrual cycle interval (day) ${ }^{\mathrm{i}}$ \\
\hline 23 & $375(7.0)$ & $213(8.9)$ \\
\hline $24-35$ & $4,798(89.7)$ & $1,953(81.4)$ \\
\hline$>35$ & $155(2.9)$ & $215(8.9)$ \\
\hline Others or not stated & $23(0.4)$ & $19(0.8)$ \\
\hline$P$ value & $<.01$ & $<.01$ \\
\hline History of abnormal pregnancy & History of abnormal pregnancy & History of abnormal pregnancy \\
\hline No & $4,851(89.5)$ & $2,120(85.9)$ \\
\hline Yes & $571(10.5)$ & $347(14.1)$ \\
\hline$P$ value & $<.01$ & $<.01$ \\
\hline \multicolumn{3}{|l|}{ Parity } \\
\hline Nullipara & $3,629(66.9)$ & $1,751(71.0)$ \\
\hline Multipara & $1,793(33.1)$ & $716(29.0)$ \\
\hline$P$ value & $<.01$ & $<.01$ \\
\hline
\end{tabular}

$B M I$, body mass index; $N S$, not significant

${ }^{\text {a }}$ Group 1 comprises women who had spontaneous pregnancy in the last year.

b Group 2 comprises women who did not have spontaneous pregnancy in the last year but were willing to become pregnant.

c Represents participants' age when they started attempting to conceive.

d Minorities included the Mongol nationality, Hui nationality, and Zang nationality.

${ }^{\mathrm{e}}$ Restricted to radioactive and toxic substances.

${ }^{\mathrm{f}}$ Included those who never smoked and used to smoke.

${ }^{g}$ Included those who never drank and used to drink.

${ }^{\mathrm{h}}$ Represents the duration of cohabitation when couples started attempting to conceive.

${ }^{\mathrm{i}}$ Included a history of stillbirth, induced labor, spontaneous abortion, and ectopic pregnancy. 
Table 2 Proportion of TTP at 3, 6, 12, 24, and 36 months among different age ${ }^{\text {a }}$ groups

\begin{tabular}{|c|c|c|c|c|c|c|c|c|c|c|}
\hline $\begin{array}{l}\text { Fertility } \\
\text { rate }\end{array}$ & $\begin{array}{l}\text { Overall } \\
\text { pop- } \\
\text { ula- } \\
\text { tion }\end{array}$ & $\begin{array}{l}\text { Overall } \\
\text { pop- } \\
\text { ula- } \\
\text { tion }\end{array}$ & $\begin{array}{l}\text { Overall } \\
\text { pop- } \\
\text { ula- } \\
\text { tion }\end{array}$ & $\begin{array}{l}\text { Overall } \\
\text { pop- } \\
\text { ula- } \\
\text { tion }\end{array}$ & $\begin{array}{l}\text { Overall } \\
\text { pop- } \\
\text { ula- } \\
\text { tion }\end{array}$ & $\begin{array}{l}\text { Overall } \\
\text { pop- } \\
\text { ula- } \\
\text { tion }\end{array}$ & $\begin{array}{l}\text { Group } \\
1^{\text {b }}\end{array}$ & $\begin{array}{l}\text { Group } \\
1^{\text {b }}\end{array}$ & $\begin{array}{l}\text { Group } \\
1^{\text {b }}\end{array}$ & $\begin{array}{l}\text { Group } \\
1^{\text {b }}\end{array}$ \\
\hline & All & $\begin{array}{l}20-24 \\
(\%)\end{array}$ & $\begin{array}{l}25-29 \\
(\%)\end{array}$ & $\begin{array}{l}30-34 \\
(\%)\end{array}$ & $\begin{array}{l}35-39 \\
(\%)\end{array}$ & $\begin{array}{l}{[?] 40} \\
(\%)\end{array}$ & All & $\begin{array}{l}20-24 \\
(\%)\end{array}$ & $\begin{array}{l}25-29 \\
(\%)\end{array}$ & $\begin{array}{l}30-34 \\
(\%)\end{array}$ \\
\hline Total & 7,889 & 3,153 & 2,321 & 642 & 549 & 58 & 5,422 & 2,297 & 1,617 & 463 \\
\hline $\begin{array}{l}3 \\
\text { months }\end{array}$ & $\begin{array}{l}1,447 \\
(18.3)\end{array}$ & $\begin{array}{l}752 \\
(23.9)\end{array}$ & $\begin{array}{l}365 \\
(15.7)\end{array}$ & $\begin{array}{l}96 \\
(15.0)\end{array}$ & $\begin{array}{l}44 \\
(8.0)\end{array}$ & $\begin{array}{l}9 \\
(15.8)\end{array}$ & $\begin{array}{l}1,447 \\
(26.7)\end{array}$ & $\begin{array}{l}752 \\
(32.7)\end{array}$ & $\begin{array}{l}365 \\
(22.6)\end{array}$ & $\begin{array}{l}96 \\
(20.7)\end{array}$ \\
\hline $\begin{array}{l}6 \\
\text { months }\end{array}$ & $\begin{array}{l}2,919 \\
(37.0)\end{array}$ & $\begin{array}{l}1,341 \\
(42.5)\end{array}$ & $\begin{array}{l}817 \\
(35.2)\end{array}$ & $\begin{array}{l}226 \\
(35.2)\end{array}$ & $\begin{array}{l}107 \\
(19.5)\end{array}$ & $\begin{array}{l}15 \\
(25.9)\end{array}$ & $\begin{array}{l}2,919 \\
(53.8)\end{array}$ & $\begin{array}{l}1,341 \\
(58.4)\end{array}$ & $\begin{array}{l}817 \\
(50.5)\end{array}$ & $\begin{array}{l}226 \\
(48.8)\end{array}$ \\
\hline $\begin{array}{l}12 \\
\text { months }\end{array}$ & $\begin{array}{l}4,216 \\
(53.4)\end{array}$ & $\begin{array}{l}1,843 \\
(58.5)\end{array}$ & $\begin{array}{l}1,217 \\
(52.4)\end{array}$ & $\begin{array}{l}353 \\
(55.0)\end{array}$ & $\begin{array}{l}161 \\
(29.3)\end{array}$ & $\begin{array}{l}25 \\
(43.9)\end{array}$ & $\begin{array}{l}4,216 \\
(77.8)\end{array}$ & $\begin{array}{l}1,843 \\
(80.2)\end{array}$ & $\begin{array}{l}1,217 \\
(75.3)\end{array}$ & $\begin{array}{l}353 \\
(76.2)\end{array}$ \\
\hline $\begin{array}{l}24 \\
\text { months }\end{array}$ & $\begin{array}{l}6,047 \\
(76.7)\end{array}$ & $\begin{array}{l}2,535 \\
(80.4)\end{array}$ & $\begin{array}{l}1,838 \\
(79.2)\end{array}$ & $\begin{array}{l}512 \\
(79.8)\end{array}$ & $\begin{array}{l}267 \\
(48.6)\end{array}$ & $\begin{array}{l}40 \\
(70.2)\end{array}$ & $\begin{array}{l}5,058 \\
(93.3)\end{array}$ & $\begin{array}{l}2,155 \\
(93.8)\end{array}$ & $\begin{array}{l}1,506 \\
(93.1)\end{array}$ & $\begin{array}{l}440 \\
(95.0)\end{array}$ \\
\hline $\begin{array}{l}36 \\
\text { months }\end{array}$ & $\begin{array}{l}6,753 \\
(85.6)\end{array}$ & $\begin{array}{l}2,756 \\
(87.4)\end{array}$ & $\begin{array}{l}2,071 \\
(89.2)\end{array}$ & $\begin{array}{l}572 \\
(89.1)\end{array}$ & $\begin{array}{l}341 \\
(62.1)\end{array}$ & $\begin{array}{l}45 \\
(79.0)\end{array}$ & $\begin{array}{l}5,260 \\
(97.0)\end{array}$ & $\begin{array}{l}2,220 \\
(96.7)\end{array}$ & $\begin{array}{l}1,579 \\
(97.7)\end{array}$ & $\begin{array}{l}455 \\
(98.3)\end{array}$ \\
\hline
\end{tabular}

${ }^{\text {a }}$ Represents women's age when they started attempting to conceive.

${ }^{\mathrm{b}}$ Group 1 comprises women who had spontaneous pregnancy in the last year.

Table 3 Association of various factors for the probability of pregnancy

\begin{tabular}{|c|c|c|}
\hline & Mean TTP & Unadjusted model \\
\hline Characteristics & & FOR \\
\hline Age, years (women) $(\%)^{b}$ & Age, years (women) $(\%)^{b}$ & Age, years (women) $(\%)^{b}$ \\
\hline $20-24$ & 15.5 & ref \\
\hline $25-29$ & 14.6 & 0.89 \\
\hline $30-34$ & 16.7 & 0.92 \\
\hline $35-39$ & 35.5 & 0.39 \\
\hline 40 & 18.0 & 0.67 \\
\hline$P$ value & & $<.001$ \\
\hline Education (women) (\%) & Education (women) (\%) & Education (women) (\%) \\
\hline Primary school and below & 24.3 & (' \\
\hline Middle school & 17.5 & 1.25 \\
\hline High school & 15.8 & 1.29 \\
\hline College and beyond & 14.8 & 1.25 \\
\hline$P$ value & & .001 \\
\hline Employment (women) (\%) & Employment (women) (\%) & Employment (women) (\%) \\
\hline Employment ${ }^{\mathrm{c}}$ & 19.0 & ref \\
\hline Unemployment & 14.2 & 1.57 \\
\hline$P$ value & & $<.001$ \\
\hline Annual household income, yuan (\%) & Annual household income, yuan (\%) & Annual household income, yuz \\
\hline$<10,000$ & 16.7 & ref \\
\hline $10,000-19,999$ & 16.9 & 0.95 \\
\hline$>20,000$ & 19.4 & 0.79 \\
\hline$P$ value & & $<.001$ \\
\hline Age, years (men) $(\%)^{b}$ & Age, years (men) $(\%)^{b}$ & Age, years (men) $(\%)^{b}$ \\
\hline
\end{tabular}




\begin{tabular}{lll}
\hline & Mean TTP & Unadjusted model \\
\hline $20-24$ & 15.3 & ref \\
$25-29$ & 14.5 & 0.95 \\
$30-34$ & 14.9 & 1.00 \\
$35-39$ & 32.0 & 0.50 \\
40 & 19.4 & 0.67 \\
$P$ value & & $<.001$ \\
Education (men) (\%) & Education (men) (\%) & Education (men) (\%) \\
Primary school and below & 24.0 & ref \\
Middle school & 17.5 & 1.31 \\
High school & 15.7 & 1.42 \\
College and beyond & 15.3 & 1.31 \\
$P$ value & & $<.001$ \\
Toxic exposure (men) ${ }^{\mathbf{d}}$ & Toxic exposure (men) ${ }^{\mathbf{d}}$ & Toxic exposure (men) \\
No & 17.1 & ref \\
Yes & 20.9 & 0.73 \\
$P$ value & & $<.001$ \\
Duration of cohabitation, years ${ }^{\mathbf{e}}$ & Duration of cohabitation, years ${ }^{\mathbf{e}}$ & 1.00 \\
Menstrual cycle interval (day) & Menstrual cycle interval (day) & Menstrual cycle interval (day) \\
23 & 16.0 & 0.81 \\
$24-35$ & 18.0 & ref \\
$>35$ & 32.1 & 0.42 \\
$P$ value & & $<.001$ \\
History of abnormal pregnancy & History of abnormal pregnancy & History of abnormal pregnanc \\
No & 16.8 & ref \\
Yes & 20.7 & 0.77 \\
$P$ value & & $<.001$ \\
Parity & Parity & Parity $^{\text {Nullipara }}$ \\
Multipara & 17.7 & ref \\
$P$ value & 16.1 & 1.08 \\
& & .010 \\
\hline
\end{tabular}

a Adjustments included age, ethnicity, educational level, employment status, history of toxic exposure, smoking and drinking status of couples, frequency of physical exercise in women, annual household income of the family, duration of cohabitation (years), menstrual cycle interval, history of abnormal pregnancy, and parity.

b Represents participants' age when they started attempting to conceive.

${ }^{\mathrm{c}}$ Included clerk, professional worker, service worker, agricultural and related worker, and factory worker.

d Restricted to radioactive and toxic substances.

e Represents the duration of cohabitation when couples started attempting to conceive.

Figure legends

Figure 1. Flow charts of data according to eligibility for inclusion in the analysis (A) and process of collecting TTP from different participants (B).

Figure 2.Estimated survival function curve for TTP, corresponding to the elapsed time from stopping contraception to confirmation of pregnancy or end of pregnancy attempt in the overall population (A) and in Group 1 (C), and sorted by age of women (B) in the overall population 
and in Group 1 (D). Group 1 comprises women who had spontaneous pregnancy in the last year. Solid lines represent the curves for the estimated TTP censored at 120 months; dashed lines represent the $\mathbf{9 5 \%}$ CIs around those curves.

Figure S1. Flow chart of multistage stratified cluster sampling strategy during participant selection.

In primary sampling units, the districts were categorized into two strata, representing high and low prevalence of infertility according to the prevalence in each district reported in 1988. Subsequently, two provinces/municipalities were randomly selected from each stratum. In secondary sampling units, townships in every province/municipality were ranked according to the local per capita gross domestic product and the number of women of childbearing age and were divided into nine strata. Subsequently, three townships were randomly selected from the highest, moderate, and lowest strata, respectively. In third sampling units, participants aged 20-49 years were identified in the selected townships; among these townships, every village/street was investigated as a unit.

\section{Hosted file}

TTP in Chinese couple -Figure 1 20.5.20.docx available at https://authorea.com/users/335602/ articles/461473-estimating-time-to-pregnancy-in-chinese-couples-a-population-based-study

\section{Hosted file}

TTP in Chinese couple -Figure 2 20.5.20.docx available at https://authorea.com/users/335602/ articles/461473-estimating-time-to-pregnancy-in-chinese-couples-a-population-based-study 